\title{
miR-564 is downregulated in gastric carcinoma and targets E2F3
}

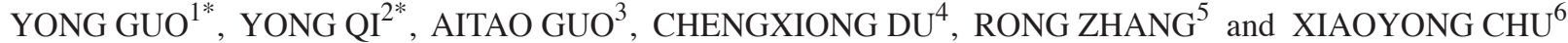 \\ ${ }^{1}$ Department of Pathology, No. 161 Hospital of the People's Liberation Army, Wuhan, Hubei 430010; ${ }^{2}$ Outpatient Department, \\ The People's Liberation Army Naval University of Engineering, Wuhan, Hubei 430033; ${ }^{3}$ Department of Pathology, \\ The General Hospital of the People's Liberation Army, Beijing 100853; ${ }^{4}$ Department of General Surgery, \\ No. 161 Hospital of the People's Liberation Army, Wuhan, Hubei 430010; ${ }^{5}$ Clinical Laboratory, \\ Liuhuaqiao Hospital, Guangzhou, Guangdong 510010; ${ }^{6}$ Medical Clinic of Military Economy \\ Academy of the People's Liberation Army, Wuhan, Hubei 430035, P.R. China
}

Received October 7, 2015; Accepted February 27, 2017

DOI: $10.3892 / \mathrm{ol} .2017 .5964$

\begin{abstract}
Numerous aberrantly expressed microRNAs (miRNAs/miRs) have been identified in gastric cancer (GC); however, only a fraction of these have been functionally investigated and novel deregulated miRNAs in GC remain to be explored. Through examining two public miRNA expression profile datasets, the present study identified aberrantly expressed miRNAs in GC. One of these miRNA, miR-564, was identified to be downregulated in GC, which was validated in tissue samples from patients with GC by reverse transcription-quantitative polymerase chain reaction analysis. Targets of miR-564 were then predicted bioinformatically, including transcription factor E2F3 (E2F3), which was identified to be functionally enriched in several cancer signaling pathways. Furthermore, overexpression of miR-564 decreased the activity of a luciferase reporter carrying the 3'-untranslated region of $\mathrm{E} 2 \mathrm{~F} 3$, in addition to the mRNA and protein level of E2F3, indicating that miR-564 directly targets E2F3. These data suggest that by targeting E2F3, miR-564 may act as a tumor suppressor gene in gastric carcinogenesis.
\end{abstract}

\section{Introduction}

Gastric cancer (GC) is a major health problem, and is one of the leading causes of morbidity and mortality worldwide, representing the second most common cause of cancer-associated mortality (1). In 2012, GC caused 723,000 mortalities worldwide (2), due to its poor prognosis and the limited efficacy

Correspondence to: Dr Yong Guo, Department of Pathology, No. 161 Hospital of the People's Liberation Army, 68 Huangpu Street, Wuhan, Hubei 430010, P.R. China

E-mail: guoyong161@sina.com

*Contributed equally

Key words: microRNA-564, microarray, downregulation, transcription factor E2F3, gastric cancer of treatment. It is widely accepted that environmental factors, including Helicobacter pylori infection (3), Epstein-Barr virus infection (4), a poor diet, smoking and obesity (5) contribute to gastric carcinogenesis. Additionally, certain genetic factors have been implicated in the development of GC, including somatic mutations, gene amplifications and deletions, epigenetic inactivation of genes and aberrant DNA methylation $(4,6)$. Molecular profiling of GC can be performed using gene expression microarray analysis or DNA sequencing (7-9), which facilitates the identification of putative biomarkers for subtype classification, prognosis and therapeutic targets. However, the molecular mechanisms underlying the progression of GC remain poorly understood.

In addition to protein coding genes, microRNAs (miRNAs/miRs) serve important roles in human carcinogenesis. miRNAs are short ( 22 nucleotides) non-coding RNAs that regulate gene expression primarily through translational repression or transcriptional degradation, and as such effect important cellular processes, including cell proliferation, cell death and tumorigenesis (10-12). Previous studies have suggested oncogenic and tumor suppressive roles for miRNAs in cancer $(13,14)$. miRNAs also have the potential to be cancer biomarkers in terms of their tissue-specific expression and aberrant expression in cancer cells (15). miRNAs can be measured through high-throughput microarray analysis. In GC, aberrant miRNA expression profiles have been associated with GC progression, prognosis and pathogenesis $(16,17)$ by perturbing the function of target genes (18-21). For example, miR-148a is significantly downregulated in GC cell lines and tissue (22-24).

Numerous aberrantly expressed miRNAs have been identified in GC; however, only a fraction of these have been functionally investigated and novel deregulated miRNAs in GC remain to be explored. In the present study, two public miRNA expression profile datasets were examined to identify novel aberrantly expressed miRNAs in GC. One of the differentially expressed miRNAs identified, miR-564, which was downregulated, was validated in the tissue samples of patients with GC patients by reverse transcription-quantitative polymerase chain reaction (RT-qPCR) analysis. The target genes of miR-564 were then predicted and it was demonstrated 
that miR-564 could bind to the 3'-untranslated region (UTR) of transcription factor E2F3 (E2F3). Finally, overexpression of miR-564 was found to significantly inhibit the mRNA and protein levels of E2F3 in GC cells. In conclusion, the results of the current study indicate that miR-564 is an important novel potential tumor suppressor gene in gastric carcinogenesis.

\section{Materials and methods}

Public miRNA microarray data processing. Two public miRNA microarray datasets for GC and normal gastric tissue were obtained from the Gene Expression Omnibus (GEO; GEO nos. GSE23739 and GSE30070). The limma software package (version 3.30.12; https://bioconductor.org/packages/release/bioc/html/limma.html) was used to determine differentially expressed miRNAs in the two data sets between GC and normal gastric tissues. The upregulated and downregulated miRNAs from the two data sets were overlapped to generate a consensus list of differentially expressed miRNAs, which was visualized as a heatmap using Multiple Experiment Viewer software (version 4.9.0; https://sourceforge.net/projects/mev-tm4/).

Prediction of miRNA targets. TargetScan (http://www. targetscan.org) was used to predict target genes for miR-564.

Functional annotation. The enrichment of KEGG pathways for targeted genes was determined by DAVID (25). Cytoscape (26) and Enrichment Map (27) were used for visualization of the network.

Patients and tissue samples. To validate the results of the miRNA microarray analysis, 8 pairs of GC and adjacent non-cancerous gastric tissue samples were obtained. All samples were obtained from patients with gastric cancer who underwent surgical resection at No. 161 Hospital of the People's Liberation Army (Wuhan, China) between May and October 2014. All the participants were histologically confirmed to have gastric adenocarcinoma and did not receive any other forms of therapy prior to the time of enrollment. Written informed consent was obtained from all patients and the procedures used in the present study were approved by the Institutional Review Board of No. 161 Hospital of the People's Liberation Army.

Total RNA extraction and RT-qPCR analysis. All tissue samples were frozen with liquid nitrogen immediately following surgical resection. For miRNA RT-qPCR analysis, total RNA was extracted from the samples using the miRNeasy Mini kit (Qiagen, Inc., Valencia, CA, USA) according to the manufacturer's protocol. For DNA RT-qPCR analysis, total RNA was extracted with TRIzol Reagent (Invitrogen; Thermo Fisher Scientific, Inc., Waltham, MA, USA) in accordance with the manufacturer's instructions. RNU6B and $\beta$-Actin were used as reference genes for quantification of the expression of miR-564 and E2F3, respectively. The sequences of these primers are listed in Table I. PCR reaction volumes used were as follows: 2X SYBR ${ }^{\circledR}$-Green Real-time PCR Master mix $5 \mu$ l (Toyobo Co., Ltd., Osaka, Japan); cDNA50 ng, forward primer and reverse primer $5 \mu \mathrm{M}$; distilled water up to the volume of $10 \mu \mathrm{l}$.
qPCR was performed at $50^{\circ} \mathrm{C}$ for $2 \mathrm{~min}$, followed by 40 cycles of $95^{\circ} \mathrm{C}$ for $15 \mathrm{sec}$ and $60^{\circ} \mathrm{C}$ for $1 \mathrm{~min}$ on an iQ5 Real-Time PCR Detection System (Bio-Rad Laboratories, Inc., Hercules, CA, USA). All reactions were carried out in triplicate. Expression was quantified using the $2^{-\Delta \Delta \mathrm{Cq}}$ method (28).

Cell culture. The GC cell line, SGC-7901 was obtained from the Institute of Biochemistry and Cell Biology of the Chinese Academy of Sciences (Shanghai, China). The cells were maintained in Dulbecco's modified Eagle medium, supplemented with $10 \%$ fetal bovine serum (Hyclone; GE Healthcare Life Sciences, Logan, UT, USA), $100 \mathrm{U} / \mathrm{ml}$ penicillin, and $100 \mu \mathrm{g} / \mathrm{ml}$ streptomycin. The cells were incubated in an atmosphere of $5 \% \mathrm{CO}_{2}$ at $37^{\circ} \mathrm{C}$.

Luciferase reporter assay. The 3'-UTR of E2F3 mRNA containing the predicted miR-564 binding site using TargetScan was amplified by PCR using the PCR Amplification kit (Takara Biotechnology Co., Ltd., Dalian, China). The PCR product was digested and cloned into the psiCHECK ${ }^{\mathrm{TM}}-2$ reporter vector (Promega Corporation, Madison, WI, USA) to produce psiCHECK-2-E2F3-3'UTR reporter plasmids. Cells were seeded in 24-well plates at an initial density of $1 \times 10^{5}$ cells/well and cultured for $24 \mathrm{~h}$ at $37^{\circ} \mathrm{C}$ in the presence of $5 \% \mathrm{CO}_{2}$. A total of $200 \mathrm{ng}$ psiCHECK-2-E2F3-3'UTR and $100 \mathrm{nmol} / \mathrm{l}$ hsa-miR-564 mimic (or miRNA mimics control, NC group) were synthesized at GenePharma Co., Ltd. (Suzhou, China) and cotransfected into the SGC7901 cells using Lipofectamine ${ }^{\circledR} 2000$ (Invitrogen; Thermo Fisher Scientific, Inc.). After $48 \mathrm{~h}$, the cells were lyzed by adding $100 \mu \mathrm{l}$ Passive Lysis Buffer (Promega Corporation; E194A) and reporter activity was determined using a Dual-Luciferase ${ }^{\circledR}$ Reporter Assay kit (Promega Corporation; E1910) according to the manufacturer's protocol.

Western blotting. Proteins were isolated via lysing cells in Cell Lysis Buffer (Cell Signaling Technology, Inc., Danvers, MA, USA) followed by centrifugation at $13,000 \mathrm{x} \mathrm{g}$ for $10 \mathrm{~min}$ at $4^{\circ} \mathrm{C}$. Protein $(10 \mu \mathrm{g} /$ lane $)$ was loaded onto a $10 \%$ gel, subjected to SDS-PAGE and subsequently transferred to a polyvinylidene difluoride membrane. Membranes were probed with polyclonal rabbit antibodies directed against anti-E2F3 (catalog no., ab50917; dilution, 1:500; Abcam, Cambridge, MA, USA) overnight at $4^{\circ} \mathrm{C}$, then incubated in horseradish peroxidase-conjugated anti-rabbit secondary antibodies (catalog no., GB23303; dilution, 1:3,000; Servicebio, Wuhan, China) for $1 \mathrm{~h}$ at room temperature. An anti- $\beta$-tubulin rabbit polyclonal antibody (catalog no., ab151318; dilution, 1:5,000; Abcam) was used as a loading control. The blot was developed using Enhanced Chemiluminescence Substrate Solution (Beyotime Institute of Biotechnology, Haimen, China) and images of the blot captured using the FluorChem ${ }^{\mathrm{TM}}$ Imaging System (ProteinSimple; Bio-Techne, Minneapolis, MN, USA). The intensity of each spot was analyzed with AlphaEaseFC ${ }^{\text {тм }}$ 4.0 imaging software (AlphaInnotech, San Leandro, CA, USA).

Statistical analysis. All data are presented as the mean \pm standard deviation of $\geq 3$ independent experiments. The results were analyzed using a two-tailed Student's t-test. $\mathrm{P}<0.05$ Results were considered statistically significant at $\mathrm{P}<0.05$. 
Table I. Primers used for quantitative polymerase chain reaction.

\begin{tabular}{lll}
\hline Gene & \multicolumn{1}{c}{ Forward (5'-3') } & \multicolumn{1}{c}{ Reverse $\left(5^{\prime}-3^{\prime}\right)$} \\
\hline RNU6B & CTCGCTTCGGCAGCACA & AACGCTTCACGAATTTGCGT \\
$\beta$-Actin & CTGGAACGGTGAAGGTGACA & AAGGGACTTCCTGTAACAATGCA \\
miR-564 & ACACTCCAGCTGGGAGGCACGGTGTCA & TGGTGTCGTGGAGTCG \\
E2F3 & GCACTACGAAGTCCAGATAGTCC & AGACTGCAGCCCATCCATTG
\end{tabular}
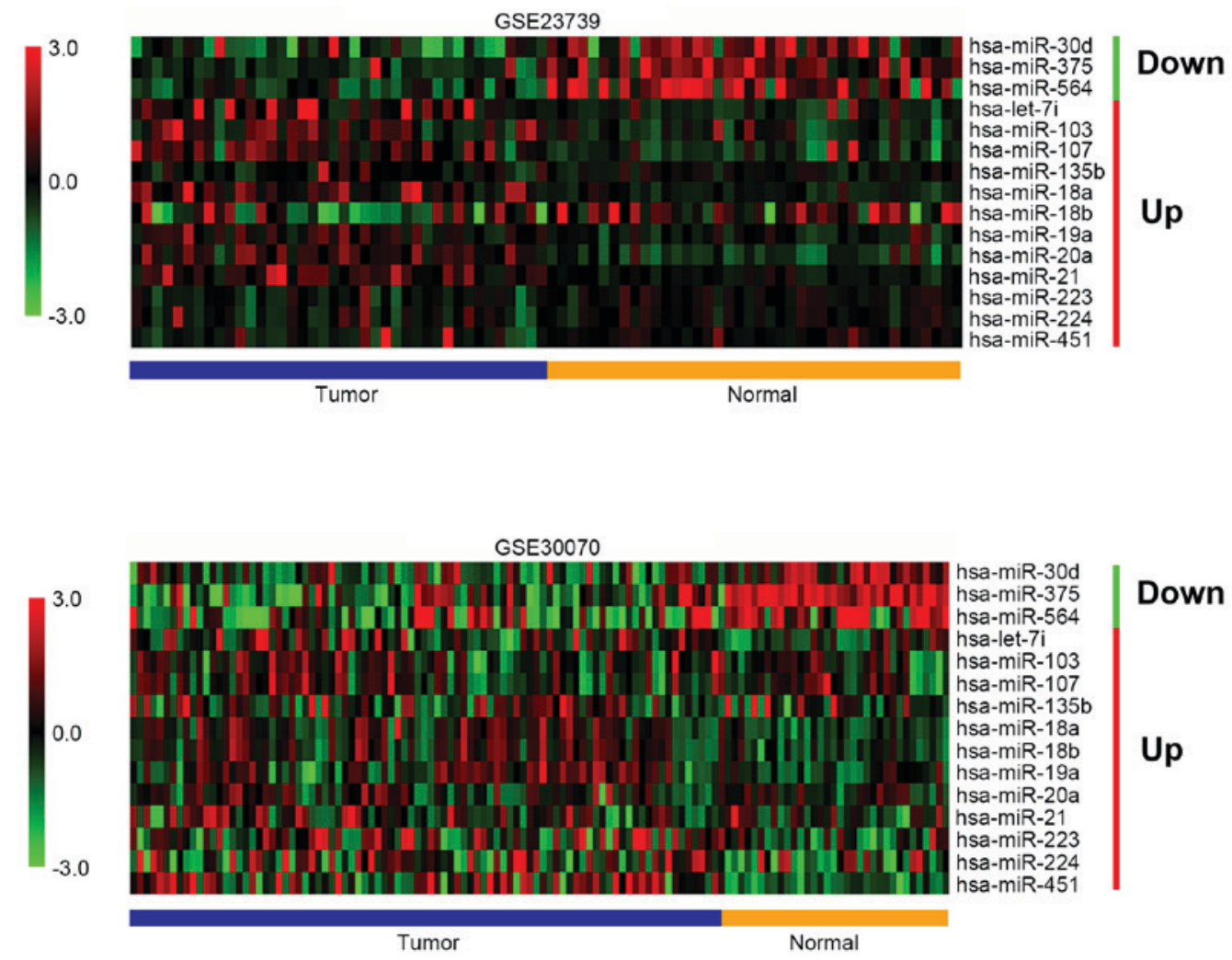

Figure 1. Identification of aberrantly expressed miRNAs in gastric carcinoma from public miRNA microarray analysis datasets GSE23739 and GSE30070. The results, presented as heatmaps, demonstrate 15 aberrantly expressed miRNAs that were consistent across the datasets. This comprised 3 downregulated and 12 upregulated miRNAs. miRNA/miR, microRNA.

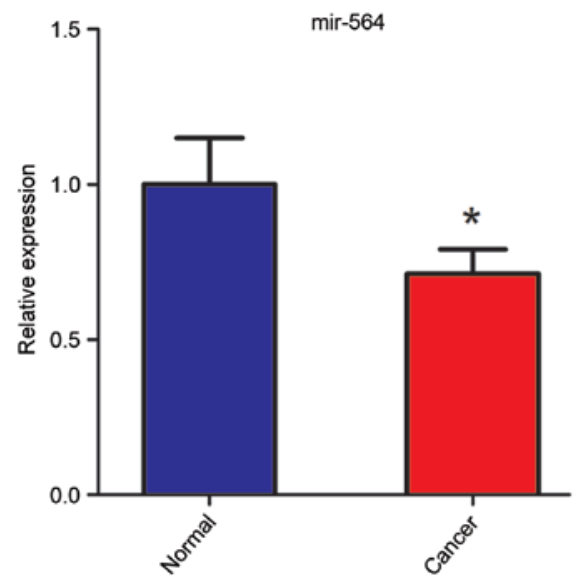

Figure 2. Reverse transcription-quantitative polymerase chain reaction analysis validation of the expression of miR-564 in patients with GC. Replicates $(n=8)$ of GC and adjacent normal tissue samples were run and the Cq values averaged. All Cq values were normalized to RNU6B. GC, gastric carcinoma. ${ }^{*} \mathrm{P}<0.05$ vs. adjacent normal tissue samples. miR, microRNA.

\section{Results}

Identification of novel aberrantly expressed miRNAs in GC. To identify novel miRNAs associated with GC, two publicly available miRNA expression profiles were analyzed. Of the two data sets, GSE23739 contained 40 GC tissue samples and 40 normal gastric tissue samples, whereas GSE30070 contained $90 \mathrm{GC}$ tissue samples and 34 normal gastric tissue samples. Differential expression analysis was performed on the datasets, then by comparing and overlapping the differentially expressed miRNAs, a list of miRNAs that were differentially expressed in GSE23739 and GSE30070 were obtained. As illustrated in Fig. 1, 3 miRNAs were downregulated in GCs and 12 miRNAs were upregulated in GCs. One of the downregulated miRNAs, miR-564, was identified to be a novel miRNA that was dysregulated in GC, though it has been reported that miR-564 was increased in H.pylori-positive compared with the $H$. pylori-negative GC tissues (29). 

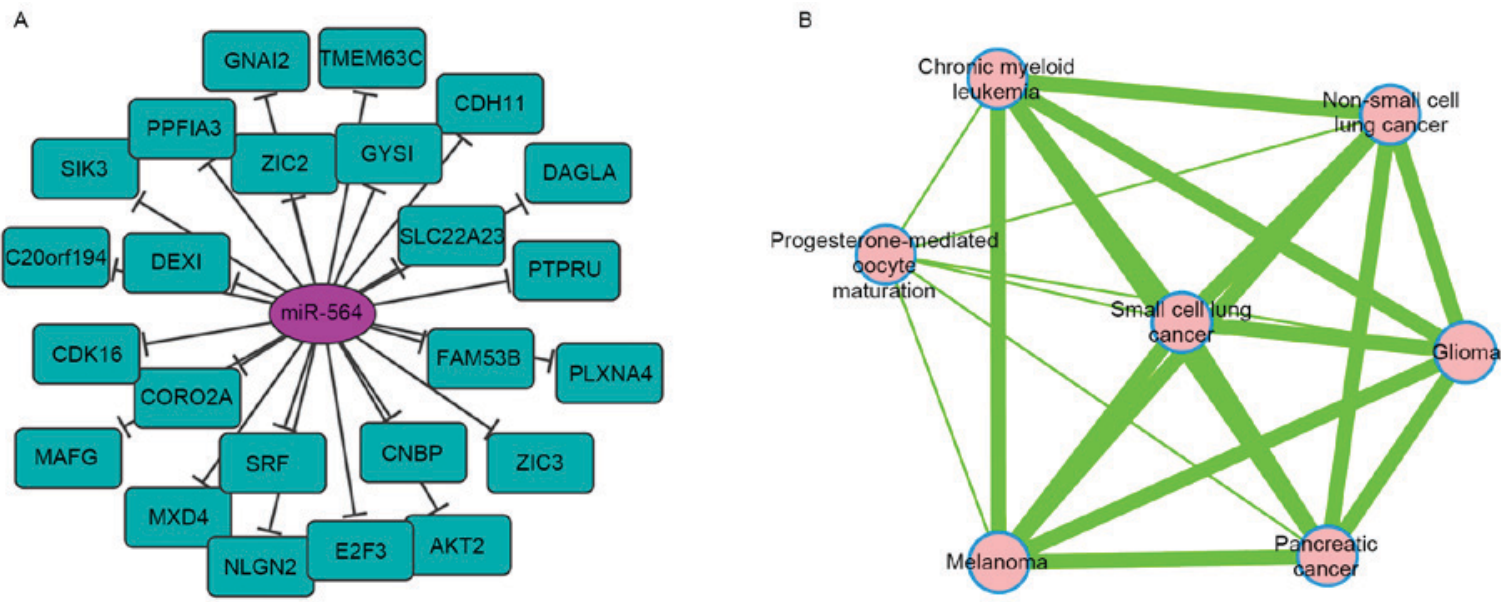

Figure 3. Prediction of target genes of miR-564. (A) miR-574-target gene network. Purple circle represents the microRNA and green circles represent the target genes. (B) Functional pathway enrichment analysis delineated the biological signaling pathways of miR-564 predicted target genes. Nodes represent enriched signaling pathways, which are grouped and annotated by their similarity according to related gene sets. The proportion of shared genes between gene sets is represented as the thickness of the green lines between nodes. miR, microRNA; E2F3, transcription factor E2F3; AKT2, AKT serine/threonine kinase 2 .

miR-564 expression is downregulated in GC. To evaluate the role of miR-564 in the development of GC, the expression levels of miR-564 were measured in 8 human primary GC tissues and paired normal adjacent gastric tissues. The results revealed that the GC samples had a significantly lower level of miR-564 expression compared with adjacent normal gastric tissue ( $\mathrm{P}<0.05$; Fig. 2). These data suggest that miR-564 is downregulated in GC and indicate that it is a potential tumor suppressor.

Predicting the putative targets of miR-564. To investigate the potential role of miR-564, target genes for this miRNA were predicted using TargetScan. As a result, 25 candidate targets were identified (Fig. 3A). Functional pathway enrichment analysis revealed that the proteins encoded by these genes were enriched in various types of cancer signaling pathways (Fig. 3B). One predicted target, E2F3, a transcriptional activator of E2F-family of transcription factors, was associated with numerous cancer-associated signaling pathways. This indicates that miR-564 regulates GC progression through targeting E2F3.

E2F3 is a direct target of miR-564 in GC cells. To validate E2F3 as a target of miR-564, luciferase reporter assays were conducted using the E2F3-3'UTR in miR-564-transfected SGC7901 cells. Position 416-422 of E2F3-3'UTR was predicted as the target binding region for miR-564 (Fig. 4A). The luciferase activity of the E2F3-3'UTR plasmid significantly decreased by $40 \%$ following treatment with the miR-564 mimic $(\mathrm{P}<0.05 \mathrm{vs}$. the $\mathrm{NC}$ group; Fig. 4B). These results indicate that miR-564 suppresses gene expression through binding to the 3'UTR of E2F3 mRNA. Moreover, RT-qPCR (Fig. 4C) and western blot (Fig. 4D) analyses demonstrated that the expression of E2F3 mRNA and protein, respectively, were decreased following treatment with the miR-564 mimic. These results indicate that E2F3 is a direct target of miR-564.

\section{Discussion}

Accumulating evidence has demonstrated that miRNAs regulate cancer development and progression by acting as tumor suppressors or oncogenes $(13,14)$. Through examining two public miRNA expression profiles the present study identified 15 aberrantly expressed miRNAs in GC, including 3 downregulated and 12 upregulated miRNAs. Some of these miRNAs, for example miR-21, have previously been demonstrated to be upregulated in GC (30). In addition, the present study identified a novel aberrantly expressed miRNA, miR-564. RT-qPCR analysis of $8 \mathrm{GC}$ tissue and adjacent normal tissue samples validated that miR-564 was downregulated in GC, which was consistent with the results of miRNA microarray analysis. miR-564 has been reported to be aberrantly expressed in breast cancer (31) and chronic myeloid leukemia (32), indicating that is serves a role in cancer development. However, the molecular mechanism underlying the downregulation of miR-564 in GC remains unknown. Genomic deletions in miRNAs have been reported as a mechanism for miRNA downregulation, including that of miR-101, -15a and -16-1 $(33,34)$. Thus, examining whether genomic loss has occurred at chromosome 3p21.31, where miR-564 is located, in GC may provide evidence to explain this. Other factors, including DNA methylation, histone modification, interactions between transcriptional suppressors and the miR-564 promoter, and post-transcriptional regulation may also serve role in the downregulation of miR-564 in GC. Further studies are required to determine the mechanism underlying miR-564 downregulation in GC.

The predicted target genes of miR-564, particularly E2F3, were functionally enriched in the signaling pathways of several cancers, including non-small cell lung cancer, glioma, melanoma, pancreatic cancer, chronic myeloid leukemia and small cell lung cancer. E2F3 is known to be a potent regulator of cell cycle progression and apoptosis, with the capacity to stimulate quiescent cells to proliferate or to induce cell apoptosis. Deregulation of E2F3, either through overexpression (35) or inactivation (36) by repressor mechanisms, is a frequent oncogenic event in human tumorigenesis. In GC, 4 miRNAs (miR-141, -449a, -145 and -125a-5p) have been reported to inhibit cancer cell proliferation through directly targeting E2F3 (37-40). Furthermore, E2F3 has been demonstrated to be upregulated in human GC tissue samples 
A

E2F3 3'UTR 5'... UAAUAGCAUUUCAAGCCGUGCCU... hsa-miR-564 3' CGGACGACUGUGGCACGGA

C

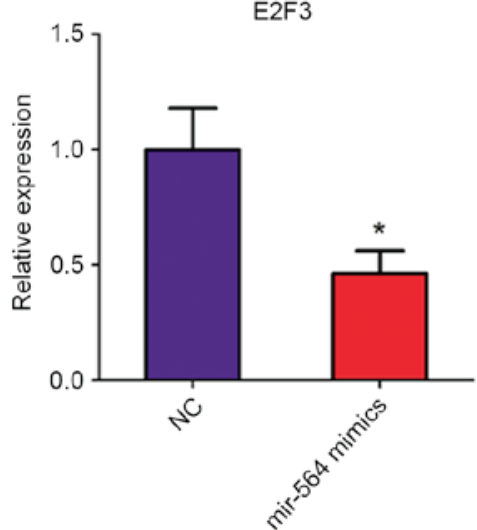

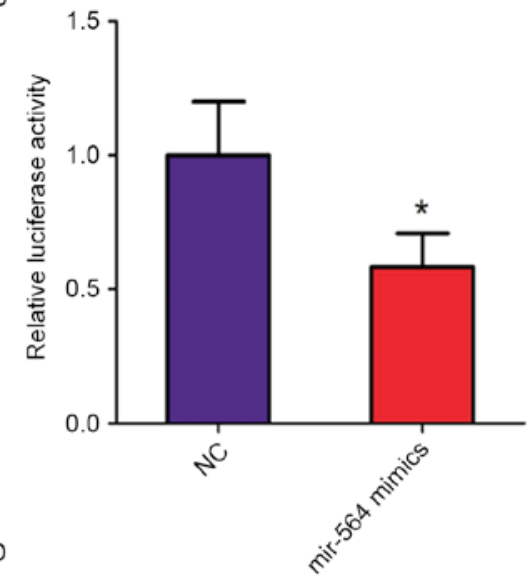

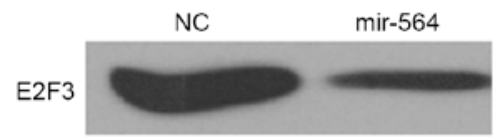

Tubulin

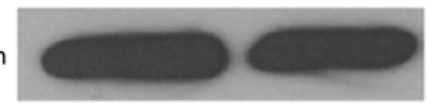

Figure 4. E2F3 is a direct target of miR-564 in SGC-7901 gastric cancer cells. (A) TargetScan predicted an miR-564 target sequence in the 3'-UTR of E2F3 mRNA. (B) E2F3-3'UTR plasmids were transfected into miR-564 mimic-treated cells and assayed for luciferase activity. (C) The mRNA levels of E2F3 were detected by reverse transcription-quantitative polymerase chain reaction analysis in cells transfected with miR-564 mimic or the NC. (D) E2F3 protein levels were detected by western blotting in cells transfected with miR-564 mimic or NC. "P<0.05 vs. the NC group. E2F3, transcription factor E2F3; miR, microRNA; UTR, untranslated region; $\mathrm{NC}$, negative control.

compared with paired normal tissues (38). The luciferase reporter assay performed in the current study confirmed that miR-564 directly binds the 3'-UTR of E2F3 mRNA to inhibit E2F3 protein translation in GC cells. In addition, overexpression of miR-564 decreased the mRNA and protein levels of E2F3. Although no cell proliferation assay was performed in the current study, the results obtained suggest that the downregulation of miR-564 serves a tumor suppressor role in $\mathrm{GC}$ and may inhibits cancer cell proliferation through directly targeting E2F3.

It should be noted that although E2F3 was demonstrated to be a direct target gene of miR-564, the potential antioncogenic effects of miR-564 may not be fully explained by its ability to regulate a single gene alone, particularly as a previous study identified that single miRNAs frequently regulate numerous genes (41). Therefore, other predicted target genes of miR-564 should be investigated in future studies. For example, another putative target of miR-564 identified in the current study, AKT serine/threonine kinase 2 (AKT2) is an essential mediator of tumorigenesis and thought to be an ideal target for the treatment of malignancies. Previous studies have reported that miRNA-137 and miRNA-29 s may target AKT2 to inhibit the tumorigenesis and invasiveness of GC cells $(42,43)$. However, the present study had several limitations, including the fact that there was no clinical data. Further studies are required to determine the effects of miR-564 in patients with
GC with different stages of cancer, and to evaluate its prognostic value.

In conclusion, the present study revealed that miR-564 is frequently downregulated in $\mathrm{GC}$ and that its potential tumor suppressor functions in GC are associated with directly targeting E2F3. These results indicate that miR-564 represents a novel target for GC therapy.

\section{References}

1. Jemal A, Bray F, Center MM, Ferlay J, Ward E and Forman D: Global cancer statistics. CA Cancer J Clin 61: 69-90, 2011

2. Ferlay J, Soerjomataram I, Dikshit R, Eser S, Mathers C, Rebelo M, Parkin DM, Forman D and Bray F: Cancer incidence and mortality worldwide: Sources, methods and major patterns in GLOBOCAN 2012. Int J Cancer 136: E359-E386, 2015.

3. Uemura N, Okamoto S, Yamamoto S, Matsumura N, Yamaguchi S, Yamakido M, Taniyama K, Sasaki N and Schlemper RJ: Helicobacter pylori infection and the development of gastric cancer. N Engl J Med 345: 784-789, 2001.

4. Cancer Genome Atlas Research Network: Comprehensive molecular characterization of gastric adenocarcinoma. Nature 513: 202-209, 2014.

5. Zhang X, Ni Z, Duan Z, Xin Z, Wang H, Tan J, Wang G and Li F: Overexpression of E2F mRNAs associated with gastric cancer progression identified by the transcription factor and miRNA co-regulatory network analysis. PLoS One 10: $\mathrm{e} 0116979,2015$.

6. Garzon R, Calin GA and Croce CM: MicroRNAs in Cancer. Annu Rev Med 60: 167-179, 2009. 
7. Tan IB, Ivanova T, Lim KH, Ong CW, Deng N, Lee J, Tan SH, $\mathrm{Wu} \mathrm{J}$, Lee $\mathrm{MH}$, Ooi $\mathrm{CH}$, et al: Intrinsic subtypes of gastric cancer, based on gene expression pattern, predict survival and respond differently to chemotherapy. Gastroenterology 141: 476-485, 2011

8. Lei Z, Tan IB, Das K, Deng N, Zouridis H, Pattison S, Chua C, Feng Z, Guan YK, Ooi CH, et al: Identification of molecular subtypes of gastric cancer with different responses to PI3-kinase inhibitors and 5-fluorouracil. Gastroenterology 145: 554-565, 2013.

9. Wang K, Kan J, Yuen ST, Shi ST, Chu KM, Law S, Chan TL, Kan Z, Chan AS, Tsui WY, et al: Exome sequencing identifies frequent mutation of ARID1A in molecular subtypes of gastric cancer. Nat Genet 43: 1219-1223, 2011.

10. Bartel DP: MicroRNAs: Genomics, biogenesis, mechanism, and function. Cell 116: 281-297, 2004.

11. Bartel DP: MicroRNAs: target recognition and regulatory functions. Cell 136: 215-233, 2009.

12. Hwang HW and Mendell JT: MicroRNAs in cell proliferation, cell death, and tumorigenesis. Br J Cancer 94: 776-780, 2006.

13. Kent OA and Mendell JT: A small piece in the cancer puzzle: MicroRNAs as tumor suppressors and oncogenes. Oncogene 25 6188-6196, 2006.

14. Calin GA and Croce CM: MicroRNA signatures in human cancers. Nat Rev Cancer 6: 857-866, 2006.

15. Gaur A, Jewell DA, Liang Y, Ridzon D, Moore JH, Chen C, Ambros VR and Israel MA: Characterization of microRNA expression levels and their biological correlates in human cancer cell lines. Cancer Res 67: 2456-2468, 2007.

16. Ueda T, Volinia S, Okumura H, Shimizu M, Taccioli C, Rossi S, Alder H, Liu CG, Oue N, Yasui W, et al: Relation between microRNA expression and progression and prognosis of gastric cancer: A microRNA expression analysis. Lancet Oncol 11: 136-146, 2010

17. Li X, Zhang Y, Zhang Y, Ding J, Wu K and Fan D: Survival prediction of gastric cancer by a seven-microRNA signature. Gut 59: 579-585, 2010.

18. Petrocca F, Visone R, Onelli MR, Shah MH, Nicoloso MS, de Martino I, Iliopoulos D, Pilozzi E, Liu CG, Negrini M, et al: E2F1-regulated microRNAs impair TGFbeta-dependent cell-cycle arrest and apoptosis in gastric cancer. Cancer cell 13 272-286, 2008

19. Bandres E, Bitarte N, Arias F, Agorreta J, Fortes P, Agirre X, Zarate R, Diaz-Gonzalez JA, Ramirez N, Sola JJ, et al: microRNA-451 regulates macrophage migration inhibitory factor production and proliferation of gastrointestinal cancer cells. Clin Cancer Res 15: 2281-2290, 2009.

20. Oh HK, Tan AL, Das K, Ooi CH, Deng NT, Tan IB, Beillard E, Lee J, Ramnarayanan K, Rha SY, et al: Genomic loss of miR-486 regulates tumor progression and the OLFM4 antiapoptotic factor in gastric cancer. Clin Cancer Res 17: 2657-2667, 2011.

21. Carvalho J, van Grieken NC, Pereira PM, Sousa S, Tijssen M, Buffart TE, Diosdado B, Grabsch H, Santos MA, Meijer G, et al: Lack of microRNA-101 causes E-cadherin functional deregulation through EZH2 up-regulation in intestinal gastric cancer. J Pathol 228: 31-44, 2012

22. Chen Z, Saad R, Jia P, Peng D, Zhu S, Washington MK, Zhao Z, $\mathrm{Xu} \mathrm{Z}$ and El-Rifai W: Gastric adenocarcinoma has a unique microRNA signature not present in esophageal adenocarcinoma. Cancer 119: 1985-1993, 2013.

23. Zheng G, Xiong Y, Xu W, Wang Y, Chen F, Wang Z and Yan Z: A two-microRNA signature as a potential biomarker for early gastric cancer. Oncol Lett 7: 679-684, 2014

24. Sakamoto N, Naito Y, Oue N, Sentani K, Uraoka N, Zarni Oo H, Yanagihara K, Aoyagi K, Sasaki H and Yasui W: MicroRNA-148a is downregulated in gastric cancer, targets MMP7 and indicates tumor invasiveness and poor prognosis. Cancer Sci 105: 236-243, 2014.

25. Huang da W, Sherman BT and Lempicki RA: Systematic and integrative analysis of large gene lists using DAVID bioinformatics resources. Nat Protoc 4: 44-57, 2009.
26. Cline MS, Smoot M, Cerami E, Kuchinsky A, Landys N, Workman C, Christmas R, Avila-Campilo I, Creech M, Gross B, et al: Integration of biological networks and gene expression data using Cytoscape. Nat Protoc 2: 2366-2382, 2007.

27. Merico D, Isserlin R, Stueker O, Emili A and Bader GD: Enrichment map: A network-based method for gene-set enrichment visualization and interpretation. PLoS One 5: e13984, 2010.

28. Livak KJ and Schmittgen TD: Analysis of relative gene expression data using real-time quantitative PCR and the 2(-Delta Delta C(T)) Method. Methods 25: 402-408, 2001.

29. Chang H, Kim N, Park JH, Nam RH, Choi YJ, Lee HS, Yoon H, Shin CM, Park YS, Kim JM and Lee DH: Different microRNA expression levels in gastric cancer depending on Helicobacter pylori infection. Gut Liver 9: 188-196, 2015.

30. Effatpanah H, Yadegarazari R, Karami M, Majlesi A, Shabab N and Saidijam M: Expression analysis of mir-21 and mir-221 in cancerous tissues from Iranian patients with gastric cancer. Iran Biomed J 19: 188-193, 2015.

31. Wang B, Li J, Sun M, Sun L and Zhang X: miRNA expression in breast cancer varies with lymph node metastasis and other clinicopathologic features. IUBMB Life 66: 371-377, 2014.

32. Rokah OH, Granot G, Ovcharenko A, Modai S, Pasmanik-Chor M, Toren A, Shomron N and Shpilberg O: Downregulation of miR-31, miR-155, and miR-564 in chronic myeloid leukemia cells. PLoS One 7: e35501, 2012.

33. Varambally S, Cao Q, Mani RS, Shankar S, Wang X, Ateeq B, Laxman B, Cao X, Jing X, Ramnarayanan K, et al: Genomic loss of microRNA-101 leads to overexpression of histone methyltransferase EZH2 in cancer. Science 322: 1695-1699, 2008.

34. Calin GA, Dumitru CD, Shimizu M, Bichi R, Zupo S, Noch E, Aldler H, Rattan S, Keating M, Rai K, et al: Frequent deletions and down-regulation of micro-RNA genes miR15 and miR16 at $13 q 14$ in chronic lymphocytic leukemia. Proc Natl Acad Sci USA 99: 15524-15529, 2002.

35. Oeggerli M, Tomovska S, Schraml P, Calvano-Forte D, Schafroth S, Simon R, Gasser T, Mihatsch MJ and Sauter G: E2F3 amplification and overexpression is associated with invasive tumor growth and rapid tumor cell proliferation in urinary bladder cancer. Oncogene 23: 5616-5623, 2004

36. Miles WO, Tschöp K, Herr A, Ji JY and Dyson NJ: Pumilio facilitates miRNA regulation of the E2F3 oncogene. Genes Dev 26: 356-368, 2012.

37. Zhou X, Ji G, Ke X, Gu H, Jin W and Zhang G: MiR-141 inhibits gastric cancer proliferation by interacting with long noncoding RNA MEG3 and down-regulating E2F3 expression. Dig Dis Sci_60: 3271-3282, 2015.

38. Li X, Li H, Zhang R and Liu J: MicroRNA-449a inhibits proliferation and induces apoptosis by directly repressing E2F3 in gastric cancer. Cell Physiol Biochem 35: 2033-2042, 2015.

39. Chang S, Gao L, Yang Y, Tong D, Guo B, Liu L, Li Z, Song T and Huang C: miR-145 mediates the antiproliferative and gene regulatory effects of vitamin D3 by directly targeting E2F3 in gastric cancer cells. Oncotarget 6: 7675-7685, 2015.

40. Xu Y, Huang Z and Liu Y: Reduced miR-125a-5p expression is associated with gastric carcinogenesis through the targeting of E2F3. Mol Med Rep 10: 2601-2608, 2014.

41. Lim LP, Lau NC, Garrett-Engele P, Grimson A, Schelter JM, Castle J, Bartel DP, Linsley PS and Johnson JM: Microarray analysis shows that some microRNAs downregulate large numbers of target mRNAs. Nature 433: 769-773, 2005.

42. Wu L, Chen J, Ding C, Wei S, Zhu Y, Yang W, Zhang X, Wei X and Han D: MicroRNA-137 contributes to dampened tumorigenesis in human gastric cancer by targeting AKT2. PLoS One 10: $\mathrm{e} 0130124,2015$.

43. Zhang H, Cheng Y, Jia C, Yu S, Xiao Y and Chen J: MicroRNA-29s could target AKT2 to inhibit gastric cancer cells invasion ability. Med Oncol 32: 342, 2015. 